\title{
A novel method of detecting raised intracranial pressure from head computed tomography using optic nerve sheath diameter
}

\author{
MG Povey ${ }^{1 *}$, FA Amey $^{1}$, CR Bassford ${ }^{2}$ \\ From ESICM LIVES 2015 \\ Berlin, Germany. 3-7 October 2015
}

\section{Introduction}

Raised intracranial pressure (ICP) can cause secondary brain injury, which is associated with severe disability and mortality [1]. Invasive ICP monitoring has been linked to increased mortality [2]. Sekhon, et al. [3] demonstrated a strong correlation between optic nerve sheath diameter (ONSD) on CT scan and ICP, with the potential to use this non-invasive method to detect raised ICP.

\section{Objectives}

To assess the efficacy of ONSD as a predictor of raised ICP and to determine whether predictive value can be improved by controlling for variables measurable on CT.

\section{Methods}

Single centre, retrospective study of patients receiving ICP monitoring during 2013. For each patient, the following measurements were recorded $(\boldsymbol{A}, \boldsymbol{B}$ and $\boldsymbol{L}$ recorded bilaterally):

- ONSD 3mm behind the globe - maximum recorded $(A)$

- ONSD half way between the globe and the superior orbital fissure (SOF) - average recorded $(\boldsymbol{B})$

- Distance from the globe to the SOF $(\boldsymbol{L})$

- Anterior-posterior diameter of the foramen magnum $(\boldsymbol{F M})$

Optic nerve ratio (ONR) and ValX were calculated using equations 1 and 2, respectively (Figyre 1). The strength of the relationship between ValX and ICP was assessed using Pearson's correlation coefficient (r). A receiver operating characteristic (ROC) curve was produced to assess the ability of ValX to predict ICP above

${ }^{1}$ Warwick University, Warwick Medical School, Coventry, United Kingdom Full list of author information is available at the end of the article
$15 \mathrm{mmHg}$. A subset was re-measured by a second assessor and interclass correlation coefficient (ICC) was used to assess inter-rater reliability.

\section{Results}

57 head CTs were identified where simultaneously recorded ICP was available. The mean value of ValX was $1.02(\mathrm{SD}=0.138)$ and mean $\mathrm{ICP}$ was $14.1 \mathrm{mmHg}$ $(\mathrm{SD}=4.8 \mathrm{mmHg})$. No correlation was identified between ICP and ONSD ( $\mathrm{r}=0.032, \mathrm{n}=57)$. There was a moderate correlation between ValX and ICP $(\mathrm{r}=0.427, \mathrm{p}=$ 0.001). The ICC was 0.98 (95\% CI 0.96 to 0.99). ValX had an area under the curve to discriminate elevated
1. $O N R=\frac{A}{B}$
2. $\operatorname{ValX}=\frac{O N R \times \boldsymbol{L}}{\boldsymbol{F M}}$

Figure 1 Calculation of ONR and ValX.

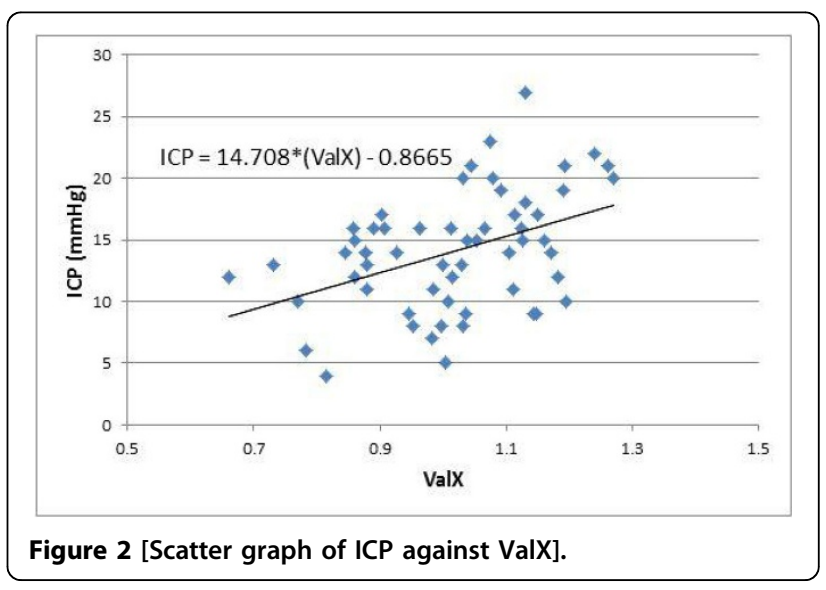

@ 2015 Povey et al.; This is an Open Access article distributed under the terms of the Creative Commons Attribution License (http:// creativecommons.org/licenses/by/4.0), which permits unrestricted use, distribution, and reproduction in any medium, provided the original work is properly cited. 


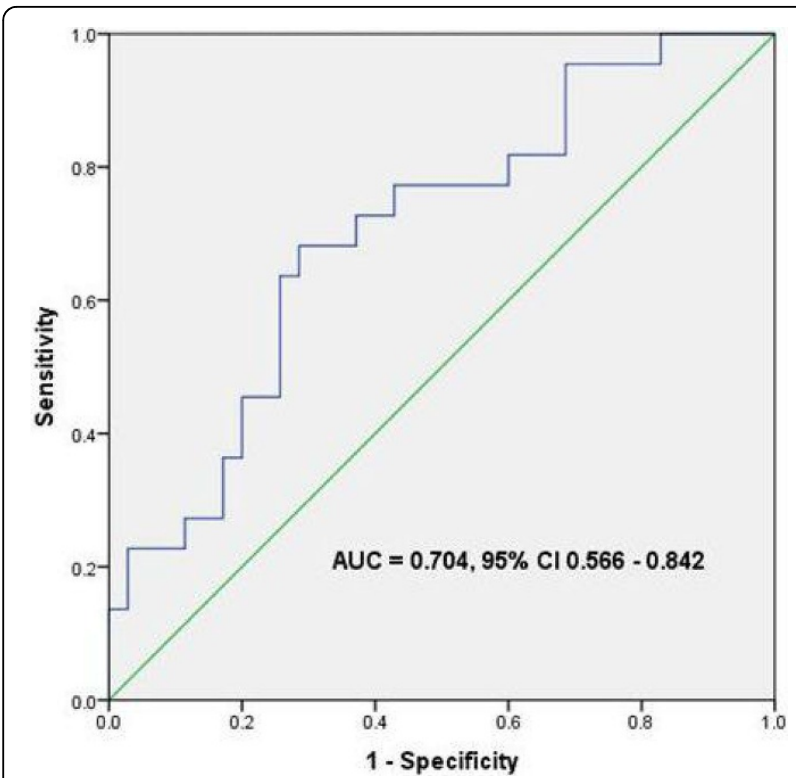

Figure 3 [ROC curve: Ability of ValX to identify ICP $>15 \mathrm{mmHg}$ ].

ICP (>15 mmHg) of 0.70 (95\% CI 0.57 to 0.84$)$. Using a cut-off of 1.03 , ValX had a sensitivity of $73 \%$, specificity of $63 \%$, positive predictive value of $55 \%$ and a negative predictive value of $79 \%$.

\section{Conclusions}

We were unable to replicate the relationship observed by Sekhon et al. [3] between ICP and ONSD. However, by controlling for measurements $L$ and $F M$, we found a moderately strong relationship. This novel technique has good inter-rater reliability. More work is required to develop this method of excluding raised ICP.

\section{Authors' details}

${ }^{1}$ Warwick University, Warwick Medical School, Coventry, United Kingdom.

${ }^{2}$ University Hospital Coventry, Critical Care Unit, Coventry, United Kingdom.

Published: 1 October 2015

\section{References}

1. Treggiari $\mathrm{M}$, et al: "Role of intracranial pressure values and patterns in predicting outcome in traumatic brain injury: a systemic review,". Neurocrit Care 2007, 6(2).

2. Shafi $S$, et al: "Intracranial pressure monitoring in brain-injured patients is associated with worsening of survival,". Journal of Trauma 2008, 64(2).

3. Sekhon S, et al: "Optic nerve sheath diameter on computed tomography is correlated with simultaneously measured intracranial pressure in patients with severe traumatic brain injury,". Intensive Care Med 2014, 40(9)

doi:10.1186/2197-425X-3-S1-A816

Cite this article as: Povey et al:: A novel method of detecting raised intracranial pressure from head computed tomography using optic nerve sheath diameter. Intensive Care Medicine Experimental 2015 3(Suppl 1):A816.

\section{Submit your manuscript to a SpringerOpen ${ }^{\circ}$ journal and benefit from:}

- Convenient online submission

- Rigorous peer review

- Immediate publication on acceptance

- Open access: articles freely available online

- High visibility within the field

- Retaining the copyright to your article 